\title{
Rare and very rare adverse effects of clozapine
}

This article was published in the following Dove Press journal:

Neuropsychiatric Disease and Treatment

6 August 2015

Number of times this article has been viewed

\author{
Pasquale De Fazio' \\ Raffaele Gaetano' \\ Mariarita Caroleo' \\ Gregorio Cerminara' \\ Francesca Maida ${ }^{2}$ \\ Antonio Bruno 3 \\ Maria Rosaria Muscatello ${ }^{3}$ \\ Maria Jose Jaén Moreno ${ }^{4}$ \\ Emilio Russo ${ }^{2}$ \\ Cristina Segura-García' \\ 'Department of Health Sciences, \\ School of Specialization in Psychiatry, \\ ${ }^{2}$ Department of Health Sciences, \\ School of Specialization in \\ Pharmacology, University "Magna \\ Graecia", Catanzaro, ${ }^{3}$ Department \\ of Neurosciences, School of \\ Specialization in Psychiatry, \\ University of Messina, Messina, Italy; \\ ${ }^{4}$ Department of Social Health \\ Sciences, Radiology and Physical \\ Medicine, University of Cordoba, \\ Cordoba, Spain
}

Correspondence: Pasquale De Fazio Department of Health Sciences, School of Specialization in Psychiatry, University "Magna Graecia", Campus Universitario, Viale Europa, 88100 Catanzaro, Italy

Tel $+39096 \mid 712393$

Fax+39096I 712393

Email defazio@unicz.it
Abstract: Clozapine (CLZ) is the drug of choice for the treatment of resistant schizophrenia; however, its suitable use is limited by the complex adverse effects' profile. The best-described adverse effects in the literature are represented by agranulocytosis, myocarditis, sedation, weight gain, hypotension, and drooling; nevertheless, there are other known adverse effects that psychiatrists should readily recognize and manage. This review covers the "rare" and "very rare" known adverse effects of CLZ, which have been accurately described in literature. An extensive search on the basis of predefined criteria was made using CLZ and its combination with adverse effects as keywords in electronic databases. Data show the association between the use of CLZ and uncommon adverse effects, including ischemic colitis, paralytic ileus, hematemesis, gastroesophageal reflux disease, priapism, urinary incontinence, pityriasis rosea, intertriginous erythema, pulmonary thromboembolism, pseudo-pheochromocytoma, periorbital edema, and parotitis, which are influenced by other variables including age, early diagnosis, and previous/current pharmacological therapies. Some of these adverse effects, although unpredictable, are often manageable if promptly recognized and treated. Others are serious and potentially life-threatening. However, an adequate knowledge of the drug, clinical vigilance, and rapid intervention can drastically reduce the morbidity and mortality related to CLZ treatment.

Keywords: clozapine, rare adverse effects, schizophrenia, atypical antipsychotic

\section{Introduction}

\section{Clinical use}

Clozapine (CLZ) is the "prototypical" of second-generation antipsychotics (APs), also named "atypical antipsychotics" (AAPs). ${ }^{1}$ It was synthesized in 1958, developed by Sandoz in 1961, and introduced in Europe in 1970. Hence, CLZ was widely viewed as the most important advance in the treatment of schizophrenia since the discovery of the first AP drugs (chlorpromazine and haloperidol in the 1950s and 1960s, respectively).

In 1975, 17 patients out of 2,660 (0.7\%) exposed to CLZ in Finland developed agranulocytosis, defined as an absolute neutrophil count $<500 / \mathrm{mm}^{3}$, and eight $(50 \%)$ of them subsequently died from secondary infections; CLZ was voluntarily withdrawn by the manufacturer. ${ }^{2}$

The effectiveness of CLZ in cases of conventional treatment-resistant schizophrenia has allowed the molecule to be reintroduced into clinical use. About $25 \%-60 \%$ of patients are unresponsive to conventional or combined pharmacological treatment (AP combined with electroconvulsive therapy or AP combined with psychotherapy). ${ }^{4,5}$ In these forms, which are defined as being "resistant", CLZ was considered the most effective $\mathrm{AP}^{6}$ for the management of severely ill schizophrenic patients who fail to respond adequately to standard APs. It was approved by the US Food and Drug Administration and health authorities in most countries, under regular hematological monitoring aimed to detect early granulocytopenia, and was first marketed in the US in January $1990 .^{7}$ 


\section{Pharmacological properties}

In comparison to traditional neuroleptics, CLZ has more robust effectiveness trials than other APs in all symptomatic schizophrenia dimensions ${ }^{8}$ and a lower incidence of extrapyramidal symptoms; ${ }^{9}$ it also has greater specificity for the limbic system, improving negative symptoms and cognitive impairment associated with schizophrenia. ${ }^{10-12}$

CLZ belongs to the family of dibenzodiazepines (8-chloro-11-(4-methyl-piperazinyl)-5H-dibenzo-[1,4]diazepine). It interacts with several different subtypes of dopamine receptors (D1, D2, D3, D4), serotonin receptors (5-HT1A, 5-HT2A, 5-HT2C, 5-HT3, 5-HT6, 5-HT7), adrenergic receptors (alpha-1, alpha-2), histaminergic receptor (H1), and muscarinic receptor (M1). ${ }^{13}$

It is often mentioned that CLZ simultaneously blocks the serotonin 5-HT2A receptors or other serotonin receptors as well as dopamine D2 receptors, suggesting that the block of serotonin receptors may prevent the Parkinson-like motor side effects of APs. ${ }^{14}$

The greater difference between the serotonin 5-HT2A receptor and D2 receptor affinities in atypical APs was not due to higher 5-HT2A affinities but due to lower D2 affinities. ${ }^{15}$

It has also been demonstrated that CLZ possesses the ability to modulate the production of pro-inflammatory cytokines such as interleukin-10 and interferon- $\gamma$ in peripheral blood cells, which also supports its potential neuroprotective effect. ${ }^{16,17}$ Moreover, an increase in plasma concentrations of CLZ leads to a significant decrease in the presence of free radicals (reactive oxygen species), which may also contribute to this latter effect. ${ }^{18}$

In addition to its indication in the treatment of resistant schizophrenia, CLZ has other important therapeutic uses. It has demonstrated efficacy in ameliorating tardive dyskinesia, mood disorders, and some neurological disorders, as well as psychosis in patients with dementia and parkinsonism. ${ }^{19}$ Only CLZ has level A evidence to support its use in Parkinson's disease patients with psychosis, whether demented or not. ${ }^{20}$ Moreover, CLZ drastically reduces mortality rates for suicide in patients with schizophrenia; in contrast, it increases the mortality rate in psychiatric patients for other rare drug-related causes, such as pulmonary embolism (PE) and CLZ-related heart problems. ${ }^{21}$

\section{Side effects}

Despite all this effectiveness, similar to many other available drugs, it has side effects that can be serious and bothersome. ${ }^{22}$ In agreement, the use of CLZ in schizophrenia is limited by the potentially fatal side effects and contraindications, which is the reason why it requires frequent monitoring. ${ }^{22}$ Approximately $17 \%$ of patients taking CLZ discontinue the treatment because of adverse effects. ${ }^{23}$

Since clinical trials are conducted under widely varying conditions, adverse reaction rates observed in clinical trials may not reflect the rates observed in clinical practice.

The most commonly reported adverse effects ( $\geq 5 \%$ ) across CLZ clinical trials ${ }^{24}$ were central nervous system reactions (sedation, dizziness/vertigo, headache, and tremor), cardiovascular reactions (tachycardia, hypotension, and syncope), autonomic nervous system reactions (hypersalivation, weight gain, drooling, sweating, dry mouth, and visual disturbances), and gastrointestinal reactions (constipation and nausea). Other adverse effects are rare or less frequent.

Adverse reactions are divided by frequency, using the following parameters: very common $(\geq 1 / 10)$, common $(\geq 1 / 100,<1 / 10)$, uncommon $(\geq 1 / 1,000,<1 / 100)$, rare $(\geq 1 / 10,000,<1 / 1,000)$, very rare $(<1 / 10,000)$, and not known (cannot be estimated from the available data). ${ }^{25}$ Table 1 shows other adverse reactions of CLZ according to their currently established frequency.

Among uncommon adverse reactions, severe cardiovascular effects are connected with the appearance of myocarditis, with $0.015 \%-1.3 \%$ of cases occurring in more than $50 \%$ of cases within the first 2 weeks of treatment, ${ }^{26}$ as well as the appearance of pericarditis and cardiomyopathy, and the lengthening of the corrected QT. ${ }^{27,28}$ The clinical presentation generally consists of heart failure including shortness of breath (60\%) and palpitations (36\%). Echocardiography at presentation showed dilated cardiomyopathy in 39\% of cases. ${ }^{29}$

Furthermore, CLZ is associated with a significant incidence of drug-induced diabetes mellitus and dyslipidemia. ${ }^{30,31}$

On the other hand, there are many other related contraindications, such as active liver disease, progressive liver disease and hepatic failure, uncontrolled epilepsy, preexisting cardiovascular disease, and severe central nervous system depression or comatose state, in alcoholic/toxic psychosis and previous hypersensitivity to CLZ. ${ }^{32}$ CLZ is also contraindicated in patients with myeloproliferative disorders and a history of toxic or idiosyncratic agranulocytosis or severe granulocytopenia. ${ }^{33}$ The underutilization of CLZ is likely related to uneasiness on the part of physicians in managing adverse effects, particularly agranulocytosis, and a reluctance by patients to submit to frequent blood sampling. ${ }^{34}$

However, an early recognition of more serious side effects may allow a better therapy management. For example, the 
Table I Adverse reactions divided by frequency regarding patients and treatment: very common $(\geq \mathrm{I} / \mathrm{I} 0)$, common $(\geq \mathrm{I} / \mathrm{I} 00,<\mathrm{I} / \mathrm{I} 0)$, uncommon $(\geq \mathrm{I} / \mathrm{I}, 000,<\mathrm{I} / \mathrm{I} 00)$, rare $(\geq \mathrm{I} / \mathrm{I} 0,000,<\mathrm{I} / \mathrm{I}, 000)$, very rare $(<\mathrm{I} / \mathrm{I} 0,000)$, and not known (cannot be estimated from the available data) (Agenzia Italiana del Farmaco [AIFA] document 06/06/2014) $)^{25}$

\begin{tabular}{|c|c|}
\hline Type and frequency & Clinical description \\
\hline \multicolumn{2}{|l|}{ Hemic/lymphatic } \\
\hline Common & $\begin{array}{l}\text { Leukopenia/decreased WBC/neutropenia/ } \\
\text { eosinophilia/leukocytosis }\end{array}$ \\
\hline Uncommon & Agranulocytosis \\
\hline Rare & Anemia \\
\hline Very rare & Thrombocytosis, thrombocytopenia \\
\hline \multicolumn{2}{|l|}{ Metabolic and nutritional } \\
\hline Common & Weight gain \\
\hline Rare & Diabetes mellitus/hyperglycemia \\
\hline Very rare & $\begin{array}{l}\text { Ketoacidosis/severe hyperglycemia/ } \\
\text { hypercholesterolemia/hypertriglyceridemia }\end{array}$ \\
\hline \multicolumn{2}{|l|}{ Psychiatric } \\
\hline Common & Dysarthria \\
\hline Uncommon & Dysphonia \\
\hline Rare & Restlessness/agitation \\
\hline \multicolumn{2}{|l|}{ Central nervous system } \\
\hline Very common & Drowsiness/sedation/vertigo \\
\hline Common & $\begin{array}{l}\text { Epileptiform movements/myoclonic jerks/ } \\
\text { extrapyramidal symptoms/akathisia/tremors/ } \\
\text { rigidity/headache }\end{array}$ \\
\hline Uncommon & Neuroleptic malignant syndrome \\
\hline Rare & Confusion/delirium \\
\hline Very rare & $\begin{array}{l}\text { Tardive dyskinesia/obsessive-compulsive } \\
\text { symptoms }\end{array}$ \\
\hline \multicolumn{2}{|l|}{ Ocular } \\
\hline Common & Visual disturbances \\
\hline \multicolumn{2}{|l|}{ Cardiovascular } \\
\hline Very common & Tachycardia \\
\hline Common & Hypertension/hypotension/syncope/ \\
\hline & ECG-cardiac abnormalities \\
\hline Rare & $\begin{array}{l}\text { Thromboembolism/arrythmia/myocarditis/ } \\
\text { pericarditis/pericardial effusion }\end{array}$ \\
\hline Very rare & Cardiac arrest/cardiomyopathy \\
\hline Unknown & Myocardial infarction/chest pain/angina \\
\hline \multicolumn{2}{|l|}{ Respiratory } \\
\hline Rare & Aspiration/pneumonia-like symptoms \\
\hline Very rare & Respiratory failure \\
\hline Unknown & Nasal congestion \\
\hline \multicolumn{2}{|l|}{ Gastrointestinal } \\
\hline Very common & Nausea/vomiting/anorexia/dry mouth \\
\hline Common & Dysphagia \\
\hline Rare & Intestinal obstruction/paralytic ileus/fecal \\
\hline Very rare & Impaction/swelling of salivary gland \\
\hline Unknown & $\begin{array}{l}\text { Diarrhea/abdominal distention/nervous } \\
\text { stomach/abnormal stools }\end{array}$ \\
\hline \multicolumn{2}{|l|}{ Hepatic } \\
\hline Common & Elevations in liver function tests \\
\hline Rare & Pancreatitis/hepatitis/cholestatic \\
\hline Very rare & Hepatic necrosis \\
\hline Unknown & $\begin{array}{l}\text { Hepatic steatosis/hepatic fibrosis/hepatic } \\
\text { cirrhosis/hepatotoxicity }\end{array}$ \\
\hline \multicolumn{2}{|l|}{ Dermatologic } \\
\hline Common & Pruritus/pallor/eczema/erythema/petechiae \\
\hline Rare & Vasculite/erythema multiforme/Stevens \\
\hline Very rare & Johnson syndrome, pityriasis rosea \\
\hline
\end{tabular}

(Continued)
Table I (Continued)

\begin{tabular}{ll}
\hline Type and frequency & Clinical description \\
\hline $\begin{array}{l}\text { Musculoskeletal } \\
\text { Unknown }\end{array}$ & Muscle weakness/muscle spasm/muscle pain \\
Urogenital & \\
Common & Urinary abnormalities \\
Very rare & Priapism/interstitial nephritis \\
Unknown & Renal failure/nocturnal enuresis \\
Other & \\
Common & Hyperthermia malignant/weakness/fever \\
Very rare & Sudden death/CPK increases \\
\hline
\end{tabular}

Abbreviations: WBC, white blood cell; ECG, electrocardiogram; CPK, creatine phosphoKinase.

monitoring system has been effective in reducing both the incidence of CLZ-related agranulocytosis and the associated mortality rate. ${ }^{34}$ Therefore, patients generally tolerate most common side effects associated with CLZ use, and appropriate medical management facilitates a maximization of the treatment benefits. Conversely, some adverse effects are not described in the data sheet, and less known by most psychiatrists because of their presence in case reports only; however, some of them are potentially fatal.

The aim of the present review is to describe the "rare" and "very rare" adverse effects related to CLZ's treatment, which are often not described in the data sheet but potentially life-threatening; we also describe strategies for their management according to literature reports, in order to provide psychiatrists and physicians with a quick reference tool that contains appropriate therapeutic measures to be taken in the case of these kinds of adverse effects. Anticipating and managing these adverse effects may be essential for a valuable therapeutic outcome.

\section{Methods}

This review considered articles and case reports that better describe rare and very rare adverse effects of CLZ, at any dose; common side effects are widely described.

The following scientific databases were consulted to find studies published in English without year limits: Medline (OvidSP), CINAHL (Ebsco), EMBASE (Ovid), PsychINFO (Ebsco), AgeLine, Cochrane Database of Systematic Reviews, and the Database of Abstracts of Reviews of Effects. Additional references were identified from the bibliographies of published articles.

Three reviewers independently inspected all study citations identified by the searches. The search was made using the terms "clozapine" and "clozapine and adverse effects" as keywords. Studies were included on the basis of the following inclusion criteria: studies in English language that clearly linked CLZ treatment with rare and very rare adverse 
effects and also included strategies for an early recognition and management of them. Articles focusing on widely known physical adverse effects or on psychiatric side effects and studies that considered CLZ in association with other psychotropic drugs were excluded. The search produced 4,090 results. Only 56 studies fulfilled the inclusion criteria and thus were selected for this review at the end of the selection, and were considered on the basis of frequency of every rare and very rare adverse effect.

\section{Results}

\section{Gastrointestinal adverse effects}

Rare adverse effects affecting the gastrointestinal system have been described in CLZ-treated patients. ${ }^{35-37}$ CLZ can affect the entire gastrointestinal system, from esophagus to rectum, and may cause bowel obstruction, ischemia, perforation, and aspiration. ${ }^{38}$

Due to its anticholinergic properties, the use of CLZ was related to varying degrees of impairment of intestinal peristalsis ranging from chronic constipation, paralytic ileus, and intestinal obstruction to fecal impaction. Epidemiological data on the occurrence of chronic constipation in treated patients are conflicting. Some surveys reported incidence between $22.8 \%$ and $33.3 \%$ of acute events of constipation in patients receiving chronic treatment, ${ }^{39}$ whereas in other studies, such incidence was as high as $60 \%{ }^{40}$ So far, seven deaths due to severe gastrointestinal complications have been reported in patients treated with CLZ (Table 2). The strategies needed to prevent the occurrence of gastrointestinal complications are a recommended dietary fiber intake, an adequate intake of liquids, especially in the presence of drooling, and adequate regular physical activity. In patients with a high risk of developing constipation, therapeutic options should always consider low doses of CLZ or association with a second AP. ${ }^{41}$ These strategies are similar to those used in the treatment of constipation caused by opioids, ${ }^{42}$ which could be useful in reducing morbidity and mortality from CLZ-induced adverse gastrointestinal effects. The use of prolonged-release formulations of naloxone or methylnaltrexone was considered by some authors for the agonist action exerted by norclozapine on opioid receptors. ${ }^{43,44}$ Another severe and rare CLZ-related effect is hematemesis (vomiting of blood). The possible pathophysiological mechanisms by which CLZ may cause severe esophagitis and subsequent hematemesis are not fully understood, but a role for the anticholinergic activity of the drug can be assumed. Antagonism of cholinergic receptors may be responsible for the reduction until abolition of esophageal motility, increased pressure in the lower sphincter tone, and overall reduction in esophageal tone. ${ }^{45,46}$

Another hypothesized pathophysiological mechanism regards the effects of $\mathrm{CLZ}$ on the regulation of vagal tone in esophageal peristalsis and consequent abolition and sialorrhea (excessive flow of saliva) not due to anticholinergic effects. $^{47}$

Although the number of cases of esophageal reflux is small, it still represents the most common gastrointestinal effect reported in CLZ-treated patients..$^{35,48,49}$ It was estimated that approximately $11 \%$ of patients treated with CLZ develop gastrointestinal symptoms similar to reflux esophagitis with endoscopic evidence within 6 weeks of treatment. ${ }^{35}$ Reflux symptoms could be due to the association between CLZ and proton pump inhibitor drugs, rather than only the use

Table 2 Death due to clozapine-associated gastrointestinal hypomotility

\begin{tabular}{|c|c|c|c|}
\hline $\begin{array}{l}\text { Patient (sex, } \\
\text { age [years]) }\end{array}$ & Presentation & $\begin{array}{l}\text { CLZ dose } \\
\text { (mg/day) }\end{array}$ & Reference \\
\hline M, 29 & $\begin{array}{l}\text { Aspiration of vomit secondary to obstruction } \\
\text { of the transverse colon }\end{array}$ & 400 & Hayes and Gibler ${ }^{40}$ \\
\hline $\mathrm{F}, 3 \mathrm{I}$ & $\begin{array}{l}\text { Large bowel obstruction with mucosal necrosis, } \\
\text { pulmonary edema, and shock }\end{array}$ & 300 & Thèret et $\mathrm{al}^{96}$ \\
\hline M, 49 & $\begin{array}{l}\text { Intermittent indigestion, nausea, chest pain, } \\
\text { and vomiting. Collapsed with pulmonary edema } \\
\text { secondary to inhalation of feculent vomit }\end{array}$ & 500 & Drew and Herdson ${ }^{97}$ \\
\hline M, 36 & Necrotizing colitis & 600 & Shammi and Remington ${ }^{98}$ \\
\hline M, 43 & $\begin{array}{l}\text { History of ulcerative esophagitis. Abdominal pain, } \\
\text { feculent vomiting, and severe fecal impaction } \\
\text { with large intestinal necrosis }\end{array}$ & - & Levin et $\mathrm{al}^{99}$ \\
\hline M, 44 & $\begin{array}{l}\text { Found dead. Evidence of pulmonary edema, } \\
\text { paralytic ileus, and gastroenteritis }\end{array}$ & - & Ferslew et al ${ }^{100}$ \\
\hline $\mathrm{F}, 47$ & Large bowel infarct & - & Flanagan et $\mathrm{al}^{101}$ \\
\hline
\end{tabular}

Note: -Data unavailable.

Abbreviations: CLZ, clozapine; $M$, male; F, female. 
of CLZ; ${ }^{46}$ in fact, there is a temporal association between gastroesophageal reflux symptoms onset and CLZ-proton pump inhibitor drug association. ${ }^{49,50}$

Ogilvie's syndrome is reported in some CLZ-treated schizophrenic patients. ${ }^{51}$ Ogilvie's syndrome is a massive dilatation of the loops of the bowel without radiological evidence of mechanical obstruction. This condition occurs more frequently in hospitalized or institutionalized patients with significant medical and surgical conditions and metabolic disorders, and in cases of spinal or retroperitoneal cord injuries. These injuries are the basis of altered regulation of the autonomic parasympathetic nervous system with suppression and enhancement of sympathetic tone; they cause intestinal atony and massive expansion of the loops.

Recognition and proper therapeutic management are essential to reduce the mortality rate, which is around $40 \%$, when it evolves to ischemia and colonic perforation. ${ }^{52}$

There are reported cases of gastrointestinal adverse events that cause acute abdomen, and so, it must be remembered that schizophrenic patients may have an altered sensitivity to painful stimuli and poor compliance during clinic visits. ${ }^{53}$ This event is very important for the acute abdomen differential diagnosis. ${ }^{54,55}$ APs can often have a sedative and modulating effect on a patient's nociceptive threshold. Another possibility is that pain perception is normal but that schizophrenic patients have difficulties in verbalizing their expression of pain. ${ }^{56}$

\section{Urogenital adverse effects}

The genitourinary adverse events described in CLZ-treated patients are mainly priapism and urinary incontinence. Priapism is a prolonged and persistent penile erection, independent from stimulation or sexual desire.$^{57}$ It is a urological emergency that, if not treated in a timely and appropriate manner, can cause permanent damage such as impotence, necrosis, and acute urinary retention. ${ }^{58}$ Most typical and atypical APs can cause priapism..$^{53}$ The first case of CLZinduced priapism was reported in 1992; this was probably caused by many factors including prolactin increase. ${ }^{59}$ In 2010, another case of a patient with CLZ-treated schizophrenia who developed a severe case of priapism was described; in this circumstance, he required surgical decompression and drug suspension. After a relative clinical stabilization period, the same patient was treated with CLZ for a new episode of psychosis and again developed priapism. ${ }^{60}$ Another patient was treated with hormone replacement therapy ( $3.5 \mathrm{mg}$ goserelin acetate every 28 days) that resolved the urological condition and allowed the patient to continue treatment with CLZ. Regular goserelin acetate administration is the pharmacological treatment of choice in patients with recurrent priapism due to its antagonistic action on testosterone plasma levels. ${ }^{61}$

Urinary continence requires a perfect balance between urethral closure and bladder detrusor muscle activity. ${ }^{62}$ CLZ-induced urinary incontinence often occurs as nocturnal enuresis ${ }^{63}$ and generally develops within the first few days after starting therapy. It may also occur after weeks or months. For some patients, this condition is temporary and self-limiting, while for others, it is permanent and requires treatment. ${ }^{64}$ The mechanism of CLZ-induced urinary incontinence is multifactorial ${ }^{65} \mathrm{CLZ}$ can reduce the internal bladder sphincter tone through its adrenergic blocking action. Incontinence can also be caused by intrinsic CLZ activity, that is, antimuscarinic action, and 5-HT2A and 5-HT2C receptor antagonisms. ${ }^{66,67}$

CLZ can cause an overactive bladder tone that results in continence impairment due to acting as a dopamine antagonist. ${ }^{68}$

CLZ $\alpha$-adrenergic receptor antagonism can be considered the major cause of urinary incontinence, ${ }^{65}$ in fact, the efficacy of pseudoephedrine has been demonstrated in incontinence due to CLZ treatment. Fifty-seven patients with schizophrenia who began CLZ treatment and developed urinary incontinence were treated with ephedrine; the dose was gradually increased to $150 \mathrm{mg} /$ day until the resolution of urologic adverse effects. Sixteen patients were treated with ephedrine, and 15 of them showed improvement after optimization of the assay. Twelve patients had complete resolution of symptoms, three a partial resolution, and only one had no response to treatment. Ephedrine did not alter patients' psychopathology.

\section{Dermatological adverse effects}

Many medications can cause skin rashes that occur in various forms and severity levels. Most of these reactions are mild; however, severe cases can lead to a decrease in the patient's quality of life. Serious reactions may include angioedema, acute generalized exanthematous reactions, Stevens-Johnson syndrome, and toxic epidermal necrolysis. Two cases of CLZ-treated patients with schizophrenia who developed angioneurotic edema have been reported; discontinuation of the drug resulted in resolution of the clinical symptoms. ${ }^{69}$

Although minor skin reactions may occur in 5\% of APstreated patients, a 54-year-old patient with schizophrenia treated for 28 days with CLZ developed a generalized rash compatible with pityriasis rosea (skin rash that usually begins 
as one large circular or oval spot on your chest, abdomen, or back), hyperthermia, and abnormal liver function tests. Discontinuation of the drug, together with corticosteroids and antihistamine treatment, led to the resolution of the clinical symptoms. ${ }^{70}$ A case of CLZ-induced flexural intertrigo (inflammation of the body folds) has also been reported, although the correlation between autoimmune mechanism and CLZ was not clarified; discontinuation of treatment resulted in resolution of the dermatological condition. ${ }^{71}$

\section{Pulmonary adverse effects}

Case reports exist linking CLZ use and onset of pulmonary thromboembolism. ${ }^{72-75}$ These events were related considering the lack of important risk factors such as hypercoagulability or previous surgery in patients who have had an adverse event. There is no definitive proof of a biological mechanism through which CLZ induces PE. It is believed that there is an indirect effect via weight increase and sedation, which correlate positively with abolition of physical activity, a recognized risk factor in the development of thromboembolic disease. ${ }^{76}$ Risk of developing PE is a rare event, but it is about 28 times higher in CLZ-treated patients compared to the general population. ${ }^{77}$ Although it is not an absolute contraindication, the potential risk of developing PE should be assessed at the beginning of CLZ treatment. The creation of a link between CLZ and PE has been described in a study in which death causes were investigated, including PE, by examining medical records of 67,072 patients with previous or current CLZ treatment. The rate ratio of deaths attributed to PE for current CLZ exposure was 5.2. ${ }^{21}$ Two case-control studies have explored the relationship between the use of first-generation APs and PE occurrence. There is no definitive evidence about a causal link between PE and use of first-generation APs, but it can be assumed that the use of low-potency first-generation APs is able to produce higher rates of PE compared to high-potency first-generation APs. ${ }^{78}$ In the case of nonspecific symptoms in CLZ-treated patients, such as dyspnea, caution is important for the suspect of PE even when there are no other critical elements. ${ }^{79}$

\section{Other "very rare" adverse effects}

\section{Pseudopheochromocytoma (severe paroxysmal hypertension)}

The rise of norepinephrine plasma levels in CLZ-treated patients is an expected effect caused by $\alpha 2$-adrenergic receptor antagonism. ${ }^{80-82}$ Increased catecholamine plasma levels cause nonspecific symptoms; however, there may be clinical scenarios that can be classified as pseudopheochromocytoma.
Clinical manifestations are related to paroxysmal or continuous catecholamine plasma secretion with hypertensive crises. Other detectable symptoms are hyperglycemia, panic attacks, and weight loss. ${ }^{83}$ There have been cases of pseudopheochromocytoma reported in CLZ-treated patients aged between 22 years and 51 years suffering from treatmentresistant schizophrenia. ${ }^{84}$ These patients were treated with CLZ (300-900 mg) for 2-18 months, and all had elevated urinary catecholamine levels and severe hypertension with no other organic causes. CLZ was discontinued resulting in normalization of blood pressure and urinary catecholamine concentration. ${ }^{85-87}$ This evidence suggests the need for routine urinary catecholamine screening and blood pressure monitoring.

\section{Periorbital edema}

There have been three reported cases of periorbital edema associated with CLZ treatment; in two cases, CLZ-treated patients $(150 \mathrm{mg} /$ day and $50 \mathrm{mg}$ /day) developed fever, blisters, and periorbital edema after few days. In both patients, laboratory tests showed neutrophilic leukocytosis. CLZ treatment was discontinued, and introduction of corticosteroids and antihistamine drugs caused complete symptoms remission within a few days; an IgE-mediated reaction to CLZ was assumed. ${ }^{69}$

Another case report describes a pretibial and periorbital edema in a CLZ-treated patient (400 mg daily) after 6 weeks of treatment. Laboratory tests showed a modest eosinophilia only. Halving the dose led to a regression of the allergic reaction; the CLZ antagonistic effect on the D4 receptor resulting in sodium retention and hypertension could explain the regression. ${ }^{88}$

\section{Parotitis (inflammation of one or both parotid glands)}

Sialorrhea in CLZ-treated patients is a known side effect, ${ }^{89}$ but it can occur in a secondary form caused by parotitis. ${ }^{90,91}$ Drug-induced parotitis is a rare adverse drug reaction. Based on the quantitative and qualitative evidence collected from the case reports, medications that are associated with drug-induced parotitis include L-asparaginase, CLZ, and phenylbutazone..$^{22}$

Parotid gland inflammation is among the least prominent side effects reported in CLZ-treated patients. The UK Medicines and Healthcare Products Regulatory Agency has collected 32 reports of parotitis in 504 cases of sialorrhea prior to January 2012. Most of the treatments were aimed at resolving sialorrhea and consequently the parotid swelling. There are 
no intervention protocols for these cases, and treatment can be anticholinergic drugs with the aim of blocking muscarinic receptors, and adrenergic drugs ( $\alpha 2$ agonists/ $\alpha 1$ antagonists) for the suppression of sympathetic stimulation. ${ }^{93}$

To the best of our knowledge, there is only one randomized trial that demonstrated a better response to treatment associated with terazosin ( $\alpha 1$ lytic) and benztropine (antimuscarinic) rather than monotherapy with either drug. ${ }^{94}$

\section{Conclusion}

It was not possible to provide details regarding the dosage and associations of CLZ with other APs in each study.

Despite the benefits in relieving positive and negative symptoms in treatment-resistant schizophrenia and other psychiatric and neurological disorders, ${ }^{19}$ the use of CLZ has been strongly limited by the possibility of the onset of severe adverse effects.

Clinical research has to concentrate on the presence, early recognition, and treatment of CLZ-related adverse effects. ${ }^{95}$ Clinical monitoring, laboratory tests, and instrumental controls for these adverse effects are very strict to limit possible complications, which may be fatal.

Some of these adverse effects are predictable, less serious, and more common and are directly related to the receptor-mediated mechanisms that can often be managed medically.

Others are rare and less known, and the hypothesized pathophysiology is not completely clear. The presence of adverse effects should not deter psychiatrists from using CLZ when it is necessary.

In the studies included in our review, many important outcomes were described. Monitoring both common and rare adverse effects could significantly reduce the disability and mortality associated to CLZ treatment. An early recognition of both more common and rare adverse effects may allow a better therapy management.

Furthermore, adherence to CLZ treatment can be significantly enhanced if patients are adequately informed about the nature and risk of its adverse effects and if the clinician recognizes and attempts to treat them. The appropriate management of other CLZ adverse effects facilitates a maximization of the benefits of CLZ treatment. Physicians and patients alike should be aware that there is a range of benefits of CLZ use that is wider than its risk.

\section{Disclosure}

All authors declare that they have no competing interests relevant to this work.

\section{References}

1. Stahl S. Essential Psychopharmacology. Neuroscientific Basis and Practical Applications (Essential Psychopharmacology Series). Cambridge: Cambridge University Press; 2008.

2. Indanpaan-Heikkila J, Alhava E, Olkinuora M, Palva IP. Agranulocytosis during treatment with clozapine. Eur J Clin Pharmacol. 1977;11(3): 193-198.

3. Kane J, Honigfeld G, Singer J, Meltzer H. Clozapine for the treatmentresistant schizophrenic. A double-blind comparison with chlorpromazine. Arch Gen Psychiatry. 1988;45(9):789-796.

4. Solanki RK, Singh P, Munshi D. Current perspectives in the treatment of resistant schizophrenia. Indian J Psychiatry. 2009;51(4):254-260.

5. Taylor S. Electroconvulsive therapy: a review of history, patient selection, technique, and medication management. South Med J. 2007; 100(8):494-498

6. Malhotra AK. Pharmacogenomics and schizophrenia: clinical implications. Pharmacogenomics J. 2001;1(2):109-114.

7. Kane J, Honigfeld G, Singer J, Melzer H; the Clozaril Collaborative Study Group. Clozapine for treatment-resistant schizophrenic: a double-blind comparison with chlorpromazine/benztropine. Arch Gen Psychiatry. 1998;45(9):789-796.

8. Gareri P, De Fazio P, Russo E, Marigliano N, De Fazio S, De Sarro G. The safety of clozapine in the elderly. Expert Opin Drug Saf. 2008;7(5): $525-538$.

9. Kumra S, Kranzler H, Gerbino-Rosen G, et al. Clozapine and "high-dose" olanzapine in refractory early-onset schizophrenia: a 12-week randomized and double-blind comparison. Biol Psychiatry. 2008;63(5):524-529.

10. Meltzer HY, McGurk SR. The effects of clozapine, risperidone, and olanzapine on cognitive function in schizophrenia. Schizophr Bull. 1999; 25(2):233-255.

11. Lindenmayer JP, Iskander A, Park M, et al. Clinical and neurocognitive effects of clozapine and risperidone in treatment-refractory schizophrenic patients: a prospective study. J Clin Psychiatry. 1998;59(10): 521-527.

12. Brar JS, Chengappa KN, Parepally H, et al. The effects of clozapine on negative symptoms in patients with schizophrenia with minimal positive symptoms. Ann Clin Psychiatry. 1997;9(4):227-234.

13. Gareri P, De Fazio P, De Fazio S, Norma Marigliano N, Ferreri Ibbadu G, De Sarro G. Adverse effects of atypical antiphychotics in the elderly. Drugs Aging. 2006;23(12):937-956.

14. Melzer HY, Matsubara S, Lee JC. Classification of typical and atypical antipsychotic drugs on the basis of dopamine D1, D2 and serotonin2 pKi values. J Pharmacol Exp Ther. 1989;251(1):238-246.

15. Kapur S, Seeman P. Does fast dissociation from the dopamine D2 receptor explain the action of atypical antipsychotics? A new hypothesis. Am J Psychiatry. 2001;158(3):360-369.

16. Song C, Lin A, Kenis G, Bosmans E, Maes M. Immunosuppressive effects of clozapine and haloperidol: enhanced production of the interleukin-1 receptor antagonist. Schizophr Res. 2000;42(2):157-164.

17. Paterson GJ, Ohashi Y, Reynolds GP, Pratt JA, Morris BJ. Selective increases in the cytokine, TNFalpha, in the prefrontal cortex of PCPtreated rats and human schizophrenic subjects: influence of antipsychotic drugs. J Psychopharmacol. 2006;20(5):636-642.

18. Gross A, Joffe G, Joutsiniemi SL, Nyberg P, Rimón R, Appelberg B. Decreased production of reactive oxygen species by blood monocytes caused by clozapine correlates with EEG slowing in schizophrenic patients. Neuropsychobiology. 2003;47(2):73-77.

19. Cohen SA, Underwood MT. The use of clozapine in a mentally retarded and aggressive population. J Clin Psychiatry. 1994;55(10):440-444.

20. Friedman JH. Parkinson disease psychosis: update. Behav Neurol. 2013; 27(4):469-477.

21. Walker AM, Lanza LL, Arellano F, Rothman KJ. Mortality in current and former users of clozapine. Epidemiology. 1997;8(6):671-677.

22. Krupp P, Barnes P. Clozapine-associated agranulocytosis: risk and aetiology. Br J Psychiatry Suppl. 1992;17:38-40.

23. Young CR, Bowers MB, Mazure CM. Management of the adverse effects of clozapine. Schizophr Bull. 1998;24(3):381-390. 
24. Gardner DM, Baldessarini RJ, Waraich P. Modern antipsychotic drugs: a critical overview. CMAJ. 2005;172(13):1703-1711.

25. Farmaciemedici.it [homepage on the Internet]. A.I.F.A. [updated June 6, 2014]. Available from: http://www.farmaciemedici.it/farmaci/ bugiardino/leponex/aifa/. Accessed February 19, 2015.

26. Kamphuis H, Arends J, Timmerman L, van Marle J, Kappert J. Myocarditis and cardiomyopathy: underestimated complications resulting from clozapine therapy. Tijdschr Psychiatr. 2010;52(4):223-233.

27. Crews MP, Dhillon GS, MacCabe JH. Clozapine rechallenge following clozapine-induced pericarditis. J Clin Psychiatry. 2010;71(7): 959-961.

28. Rathore S, Masani ND, Callaghan PO. Clozapine-induced effusoconstrictive pericarditis. Case report and review of the literature. Cardiology. 2007;108:183-185.

29. Alawami M, Wasywich C, Cicovic A, Kenedi C. A systematic review of clozapine induced cardiomyopathy. Int J Cardiol. 2014;176(2): 315-320.

30. Lamberti JS, Olson D, Crilly JF, et al. Prevalence of the metabolic syndrome among patients receiving clozapine. Am J Psychiatry. 2006; 163(7):1273-1276.

31. Safferman A, Lieberman J, Kane J, Szymanski S, Kinon B. Update on the clinical efficacy and side effects of clozapine. Schizophr Bull. 1991;17(2): 247-261.

32. Naheed M, Green B. Focus on clozapine. Curr Med Res Opin. 2001;17(3): 223-229.

33. Velayudhan R, Kakkan S. Late onset clozapine induced agranulocytosis. Indian J Psychol Med. 2014;36(4):425-427.

34. Alvir JM, Lieberman JA. Agranulocytosis: incidence and risk factors. J Clin Psychiatry. 1994;55(suppl B):137-138.

35. Laker M, Cookson J. Reflux oesophagitis and clozapine. Int Clin Psychopharmacol. 1997;12(1):37-39.

36. Townsend G, Curtis D. Case report: rapidly fatal bowel ischaemia on clozapine treatment. BMC Psychiatry. 2006;6:43.

37. Rege S, Lafferty T. Life-threatening constipation associated with clozapine. Australas Psychiatry. 2008;16(3):216-219.

38. Palmer SE, McLean RM, Ellis PM, Harrison-Woolrych M. Lifethreatening clozapine-induced gastrointestinal hypomotility: an analysis of 102 cases. J Clin Psychiatry. 2008;69(5):759-768.

39. Lieberman JA, Safferman AZ, Pollack S, et al. Clinical effects of clozapine in chronic schizophrenia: response to treatment and predictors of outcome. Am J Psychiatry. 1994;151(12):1744-1752.

40. Hayes G, Gibler B. Clozapine-induced constipation (letter). Am J Psychiatry. 1995;152(2):298.

41. Alexopoulos GS, Streim J, Carpenter D, Docherty JP; Expert Consensus Panel for Using Antipsychotic Drugs in Older Patients. Using antipsychotic agents in older patients. J Clin Psychiatr. 2004;65(suppl 2): 5-99.

42. Holzer P, Ahmedzai SH, Niederle N, et al. Opioid-induced bowel dysfunction in cancer-related pain: causes, consequences, and a novel approach for its management. J Opioid Manag. 2009;5(3):145-151.

43. Baker DE. Methylnaltrexone bromide: new drug for the treatment of opioid induced bowel dysfunction. Rev Gastroenterol Disord. 2009; 9(3):E84-E93.

44. Onali P, Olianas MC. N-Desmethylclozapine, a major clozapine metabolite, acts as a selective and efficacious delta-opioid agonist at recombinant and native receptors. Neuropsychopharmacology. 2007; 32(4):773-785.

45. Tomer T, Jonathan B, Alan M. Death from clozapine-induced constipation: case report and literature review. Psychosomatics. 2002;43(1): 71-73.

46. Van Soest E, Dieleman J, Kuipers E. The effect of anticholinergic agents on gastrooesophageal reflux and related disorders. Expert Opin Drug Saf. 2008;7(2):173-180.

47. Praharaj SK, Arora M, Gandotra S. Clozapine-induced sialorrhea: pathophysiology and management strategies. Psychopharmacology (Berl). 2006;185(3):265-273.
48. Baker RW, Chengappa KN. Gastroesophageal reflux as a possible result of clozapine treatment. J Clin Psychiatry. 1998;59(5):257.

49. van Veggel M, Olofinjana O, Davies G, Taylor D. Clozapìne and gastrooesophageal reflux disease (GORD) - an investigation of temporal association. Acta Psychiatr Scand. 2012;127(1):69-77.

50. Taylor D, Olofinjana $\mathrm{O}$, Rahimi T. Use of antacid medication in patients receiving clozapine: a comparison with other second generation antipsychotics. J Clin Psychopharmacol. 2010;30(4):460-461.

51. de Bruin GJ, Bac DJ, van Puijenbroek EP, van der Klooster JM. Ogilvie Syndrome induced by clozapine. Ned Tijdschr Geneeskd. 2009; 153:B437.

52. Saunders MD, Kimmey MB. Systematic review: acute colonic pseudoobstruction. Aliment Pharmacol Ther. 2005;22(10):917-925.

53. Dworkin RH. Pain insensitivity in schizophrenia: a neglected phenomenon and some implications. Schizophr Bull. 1994;20(2):235-248.

54. Bickerstaff LK, Harris SC, Leggett RS, Cheah KC. Pain insensitivity in schizophrenic patients. A surgical dilemma. Arch Surg. 1988;123(1): 49-51.

55. Rosenthal SH, Porter KA, Coffey B. Pain insensitivity in schizophrenia. Case report and review of the literature. Gen Hosp Psychiatry. 1990; 12(5):319-322.

56. Potvin S, Stip E, Tempier A, et al. Pain perception in schizophrenia: no changes in diffuse noxious inhibitory controls (DNIC) but a lack of pain sensitization. Psychiatr Res. 2008;42(12):1010-1016.

57. Keoghane SR, Sullivan ME, Miller MA. The aetiology, pathogenesis and management of priapism. BJU Int. 2002;90(2):149-154.

58. Reif R, Výborný K. Priapism: a urological emergency. Acta Univ Palacki Olomuc Fac Med. 1993;135:59-63.

59. Compton MT, Miller AH. Sexual side effects associated with conventional and atypical antipsychotics. Psychopharmacol Bull. 2001; 35(3):89-108

60. Seftel A, Saenz de Tejada I, Szetela B, Cole J, Goldstein I. Clozapineassociated priapism: a case report. J Urol. 1992;147(1):146-148.

61. Mulhall JP, Kaminetsky JC, Althof SE, et al. Correlations with satisfaction measures in men treated with phosphodiesterase inhibitors for erectile dysfunction. Am J Mens Health. 2011;5(3):261-271.

62. Hanes A, Lee Demler T, Lee C, Campos A. Pseudoephedrine for the treatment of clozapine-induced incontinence. Innov Clin Neurosci. 2013; 10(4):33-35.

63. Harrison-Woolrych M, Skegg K, Ashton J, Herbison P, Skegg DC. Nocturnal enuresis in patients taking clozapine, risperidone, olanzapine, and quetiapine: comparative cohort study. Br J Psychiatry. 2011; 199(2):140-144.

64. Lin CC, Bai YM, Chen JY, Lin CY, Lan CY, Lan TH. A retrospective of clozapine and urinary incontinence in Chinese in-patients. Acta Psychatr Scand. 1999;100(2):158-161.

65. Fuller MA, Borovicka MC, Jaskiw GE, Simon MR, Kwon K, Konicki PE. Clozapine-induced urinary incontinence: incidence and treatment with ephedrine. J Clin Psychiatry. 1996;57(11):514-518.

66. Warner JP, Harvey CA, Barnes TR. Clozapine and urinary incontinence. Int Clin Psychopharmacol. 1994;9(3):207-209.

67. Thor KB, Donatucci C. Central nervous system control of the lower urinary tract: new pharmacological approaches to stress urinary incontinence in women. J Urol. 2004;172(1):27-33.

68. Clark N. Conventional antipsychotic and clozapine-induced urinary incontinence. J Coll Psychiatr Neurolog Pharma. 2003;2:1-8.

69. Mishra B, Sahoo S, Sarkar S, Akhtar S. Clozapine-induced angioneurotic edema. Gen Hosp Psychiatry. 2007;29(1):78-80.

70. Lai YW, Chou CY, Shen WW, Lu ML. Pityriasis rosea-like eruption associated with clozapine: a case report. Gen Hosp Psychiatry. 2012; 34:e5-e7.

71. Rao A, Francis N, Morar N. Clozapine-induced symmetrical drugrelated intertriginous and flexural exanthema: first reported cases. Br J Dermatol. 2012;166(5):1142-1143.

72. Srihari VH, Lee TW. Pulmonary embolism in a patient taking clozapine. BMJ. 2008;336(7659):1499-1501. 
73. Tripp AC. Non-fatal pulmonary embolus associated with clozapine treatment: a case series. Gen Hosp Psychiatry. 2011;33(1):e5-e6.

74. Joksovic PM, Chiles C. Cardiac arrest and pulmonary embolism after clozapine titration. Prim Care Companion CNS Disord. 2011;13(2): MC3184584.

75. Munoli RN, Praharaj SK, Bhat SM. Clozapine-induced recurrent pulmonary thromboembolism. J Neuropsychiatry Clin Neurosci. 2013; 25(3):E50-E51.

76. Hägg S, Jönsson AK, Spigset O. Risk of venous thromboembolism due to antipsychotic drug therapy. Expert Opin Drug Saf. 2009;8(5): 537-547.

77. Paciullo CA. Evaluating the association between clozapine and venous thromboembolism. Am J Health Syst Pharm. 2008;65(19): 1825-1829.

78. Zornberg GL, Jick H. Antipsychotic drug use and risk of first-time idiopathic venous thromboembolism: a case-control study. Lancet. 2000; 356(9237):1219-1223.

79. Parkin L, Skegg DC, Herbison GP, Paul C. Psychotropic drugs and fatal pulmonary embolism. Pharmacoepidemiol Drug Saf. 2003; 12(8):647-652.

80. Davidson M, Kahn RS, Stern RG, et al. Treatment with clozapine and its effect of plasma homovanillic acid and norepinephrine concentrations in schizophrenia. Psychiatry Res. 1993;46(2):151-163.

81. Breier A, Buchanan RW, Waltrip RW, Listwak S, Holmes C, Goldstein DS The effect of clozapine on plasma norepinephrine: relationship to clinical efficacy. Neuropsychopharmacology. 1994;10(1):1-7.

82. Pickar D, Owen RR, Litman RE, Konicki E, Gutierrez R, Rapaport MH Clinical and biologic response to clozapine in patients with schizophrenia: Cross-over comparison with fluphenazine. Arch Gen Psychiatry 1992;49(5):345-353.

83. Walther MM, Keiser HR, Linehan WM. Pheochromocytoma: evaluation, diagnosis, and treatment. World J Urol. 1999;17(1):35-39.

84. Krentz AJ, Mikhail S, Cantrell P, Hill GM. Pseudophaeochromocytoma syndrome associated with clozapine. BMJ. 2001;322(7296):1213.

85. Li JK, Yeung VT, Leung CM, et al. Clozapine: a mimicry of phaeochromocytoma. Aust NZ J Psychiatry. 1997;31(6):889-891.

86. Prasad SE, Kennedy HG. Pseudophaeochromocytoma associated with clozapine treatment. Ir J Psych Med. 2003;20:132-134.
87. Akinsola O, Ong K. Pseudophaeochromocytoma associated with Clozapine Therapy: a case report. Afr J Psychiatry. 2011;14(5):406-408.

88. Durst R, Raskin S, Katz G, Zislin J, Durst R. Pedal edema associated with clozapine use. Isr Med Assoc J. 2000;2(6):485-486.

89. Sockalingam S, Shammi C, Remington G. Clozapine-induced hypersalivation: a review of treatment strategies. Can J Psychiatry. 2007;52(6): 377-384.

90. Brodkin E, Pelton G, Price L. Treatment of clozapine-induced parotid gland swelling. Am J Psychiatry. 1996;152(3):445.

91. Robinson D, Fenn H, Yesavage J. Possible association of parotitis with clozapine. Am J Psychiatry. 1995;152(2):297-298.

92. Brooks KG, Thompson DF. A review and assessment of drug-induced parotitis. Ann Pharmacother. 2012;46(12):1688-1699.

93. Immadisetty V, Agrawal P. A successful treatment strategy for clozapine-induced parotid swelling: a clinical case and systematic review. Ther Adv Psychopharmacol. 2012;2(6):235-239.

94. Reinstein M, Sirotovskya L, Chasonov M. Comparative efficacy and tolerability of benzatropine and terazosin in the treatment of hypersalivation secondary to clozapine. Clin Drug Investig. 1999;17:97-102.

95. Conley RR, Kelly DL. Second-generation antipsychotics for schizophrenia: a review of clinical pharmacology and medication-associated side effects. Isr J Psychiatry Relat Sci. 2005;42(1):51-60.

96. Théret L, Germail ML, Burde A. Current aspects of the use of clozapine in the Chalons-surMarn Psychiatric Hospital: intestinal occlusion with clozapine. Ann Med Psychol. 1995;153(7):474- 477.

97. Drew L, Herdson P. Clozapine and constipation: a serious issue. Aust NZ J Psychiatry. 1997;31(1):149-150.

98. Shammi CM, Remington G. Clozapine-induced necrotizing colitis. J Clin Psychopharmacol. 1997;17(3):230-232.

99. Levin TT, Barrett J, Mendelowitz A. Death from clozapine-induced constipation: a case report and literature review. Psychosomatics. 2002; 43(1):71-73.

100. Ferslew KE, Hagardorn AN, Harlan GC, McCormick WF. A fatal drug interaction between clozapine and fluoxetien. J Forensic Sci. 1998; 43(5):1082-1085.

101. Flanagan RJ, Ball RY. Gastrointestinal hypomobility: an under-recognised life-threatening adverse effect of clozapine. Forensic Sci Int. 2011; 206(1-3):e31-e36.
Neuropsychiatric Disease and Treatment

\section{Publish your work in this journal}

Neuropsychiatric Disease and Treatment is an international, peerreviewed journal of clinical therapeutics and pharmacology focusing on concise rapid reporting of clinical or pre-clinical studies on a range of neuropsychiatric and neurological disorders. This journal is indexed on PubMed Central, the 'PsycINFO' database and CAS,

\section{Dovepress}

and is the official journal of The International Neuropsychiatric Association (INA). The manuscript management system is completely online and includes a very quick and fair peer-review system, which is all easy to use. Visit http://www.dovepress.com/testimonials.php to read real quotes from published authors. 